\title{
TREATMENT FOR LATERAL EPICONDYLITIS: VARIABLES RELATED TO RECOVERY
}

\author{
Susan G. GERBERICH, PhD* and J. D. PRIEST, MDt \\ *Director of Research, Institute for Athletic Medicine and Assistant Professor, School of Public Health, \\ University of Minnesota, Minneapolis, Minnesota \\ tAssociate Medical Director, Institute for Athletic Medicine and Clinical Associate Professor, Department of Orthopaedics, \\ University of Minnesota, Minneapolis, Minnesota
}

\begin{abstract}
The purpose of this study was to determine the effectiveness of a treatment regime utilised for lateral epicondylitis that is designed to expedite return to activity and to identify variables related to treatment outcomes. Patients treated in a sports medicine clinic between 1978 and 1980 received, by mail, a brief questionnaire investigating the variables of the injuries and level of success of the treatment. Specific techniques ensured confidentiality and validation of information.

Through the analyses conducted, an inverse relationship in the total group between the level of success and the duration of pain was documented; for example, the mean durations of pain, 17.3 months, 10.3 months, and 6.3 months correlated, respectively, with the levels of success, 0 (no recovery), 2 (moderate recovery), and 4 (complete recovery). In addition,the application of multiple risk factor analysis, incorporating a maximum of eight variables, identified the degree of pain prior to treatment as the most important predictor of complete recovery; the greater the pain the more likely the complete success of the treatments. The implications of these findings include a need for early case-finding to elicit the most favourable outcomes of the treatment regime studied.
\end{abstract}

Key words: Lateral epicondylitis, Tennis elbow, Elbow injuries, Treatment.

\section{INTRODUCTION}

Approximately 13 million people in the United States (US) played tennis in the early 1970's. A recent estimate by the US Department of the Interior indicates that more than $\mathbf{4 0}$ million Americans currently play tennis. (US News and World Report, 1979). Of these tennis participants, one-third to one-half may experience the affliction known as lateral epicondylitis or "tennis elbow" (Priest et al, Part 1, 1980; Priest et al, Part 2, 1980; Allman, 1975). The symptoms of tennis elbow occur over the lateral humeral epicondylar areas in an advanced case, sharp discomfort is felt over the lateral epicondyle upon pronation and supination of the forearm, or upon flexing and extending the elbow. In a most advanced case, the patient may be unable to pick up a teacup because of excessive pain over this region of the elbow (Priest, 1976). Moreover, through a recent comprehensive epidemiological study, the average length of a single occurrence of such pain was reported as 9.6 months (10.7 months, men; 8.5 months, women) (Priest et al, Part 2, 1980).

Tennis elbow is experienced by athletes and non-athletes, alike. Carpenters, dentists, surgeons, or anyone involved in an activity or occupation requiring repetitive rotation of the forearm, or wrist flexion and extension, are prone to develop lateral epicondylitis. While many authors have advocated changing the title of the condition, the name "tennis elbow" persists.

No agreement exists as to the exact aetiology of this condition. That the cause of "tennis elbow" has remained a mystery, is doubtless the reason that therapy for this condition has been highly variable. In 1967, Friedlander et al (1967) listed 43 forms of conservative management for

Correspondence and reprint requests to:

Dr. Susan Goodwin Gerberich, PhD

Director of Research

Institute for Athletic Medicine

606 Twenty-Fourth Avenue South

Minneapolis, Minnesota 55454

Portions of this paper were presented at the American Orthopaedic Society for Sports Medicine, Williamsburg, Virginia, 27 July, 1983. tennis elbow, including radiation, manipulation, rest, immobilisation, local injection, systemic medication, and physiotherapy. Since this time, the use of acupuncture, the hinged elbow brace described by llfeld and Field (1966) the proximal forearm band, described by Froimson (1971), and counterforce bracing described by Nirschl (1974) have been utilised to varying degrees. Surgical intervention can be successful; but, is usually reserved for recalcitrant cases (Nirschl, 1979) not responding to conservative management after one or two years.

To this time, few studies have been utilised to analyse the effectiveness of specific treatments. The purpose of this study was to determine the effectiveness of a treatment regime for lateral epicondylitis employed in a sports medicine clinic since 1977 and to analyse the variables associated with the effectiveness of this treatment. The work was carried out at the Institute for Athletic Medicine and the University of Minnesota, Minneapolis, Minnesota.

\section{METHODS AND MATERIALS}

In 1981, following clearance by the Committee on Human subjects in Research, all patients treated in the clinic for lateral epicondylitis between 1978 and 1980 received, by mail, an informed consent form and a brief questionnaire investigating the variables of the injury and level of success of the treatment. A total of three mailings that included firstclass postage-paid return envelopes were utilised to maximise the percentage of returns.

The treatment regime involved three main components: 1. Electro-galvanic stimulation (EGS), whereby pads are placed over the medial and lateral epicondyles at 80 pulses/second for 20 minutes at a voltage setting just below the level of muscle contraction.

2. Ultrasound, applied over the lateral epicondyle, and into the common extensor tendons if indicated, with intensity to tolerance of patient for six minutes; application of a cream containing $10 \%$ hydrocortisone was utilised in conjunction with this component if the client was not pain-free following four treatments (Griffin et al, 1967; Griffin and Touchstone, 1963 and 1965; Kleinkort and Wood, 1975). 
3. Whirlpool at $108-110^{\circ} \mathrm{F}\left(42.2-43.3^{\circ} \mathrm{C}\right)$ for 20 minutes. Treatments were continued until pain was resolved and/ or a total of 15 treatments, over a period of six weeks, had been completed. If pain was not resolved at the end of 15 treatments, patients were referred to their respective physicians for further evaluation.

Medical records were also examined for consistency in the treatment programme from one subject to another. In addition, information, relevant to the injury, including duration of pain and treatment variables, was verified through these records. Cases involving previous surgery, steroid injections, and the involvement of multiple symptom sites were deleted for the final analysis. As a result, 82 cases met the criteria for inclusion. Specific techniques, including the use of code numbers and reporting of aggregate data, ensured confidentiality.

Analyses were conducted through computer application utilising the Statistical Package for the Social Sciences. Specific techniques, including Chi-square tests, t-tests, and regression analysis, were applied as appropriate. In addition, multiple risk factor analyses, utilising logistic regression (Cox, 1970; Dixon et al, 1981) were conducted to determine the best combination of variables that would predict complete recovery, following treatment for lateral epicondylitis. The combination of independent variables included in the multiple risk factor analyses were (1) age; (2) gender; (3) duration of pain; (4) degree of pain prior to treatment; (5) degree of activity cessation during the treatment programme; (6) use of hydrocortisone cream in the treatment programme; $(7)$ total number of treatments administered; and $(8)$ the time period during which the treatments were administered. Using the formula:

$$
E(y)=\delta=\frac{e^{\beta^{x}}}{1+e^{\beta^{x}}}
$$

$y$ denotes the dependent variable or complete recovery versus not complete recovery and $x$ denotes the independent variables (i.e. the eight variables noted above). The programme proceeds in a stepwise manner, entering or removing one term from the model at each step until the best combination of variables to predict complete recovery is identified. In all statistical testing, a significance level of 0.05 was used.

\section{RESULTS}

Of 82 cases meeting the criteria for inclusion, 60 complete case responses were obtained and entered into the final analyses. These cases included 32 males (53 percent) and 28 females (47 percent).

The mean age of these individuals was 43 years (S.E. $=1.1$ ), with a range between 26 and 63 years. This was not significantly different between males (42.7 years) and females (43.8 years).

Given the possible responses of "slight", "moderate", or "great", with regard to the level of pain perceived by the subject just prior to treatment, the majority indicated either great (53 percent) or moderate (45 percent) (Fig. 1). No statistically significant differences were found in the total mean differences between males and females. However, much greater percentages of the females (64 percent) perceived their pain as "great", in contrast to the males (44 percent).

As shown in Fig. 2, the mean duration of pain experienced by the total subjects prior to treatment was 9.8 months with statistically significant differences between males ( 8.3 months; S.E. 1.4) and females (11.4 months; S.E. 3.1). Degree of pain was not related to the duration of pain $(r=0.1)$.

In response to the question, "What activity(ies) was primarily associated with the original onset of your pain?" tennis was identified by 42 percent of the subjects with some differences observed between females (50 percent) and males ( 34 percent). Golf was identified by both male and female subjects (12 percent of the total); 16 individuals ( 27 percent) reported that more than one activity was associated with the onset of pain (Table I).

The mean number of treatments received by the subjects was 12.8 , with no significant differences between the sexes (Table II). Of the 60 cases, 41 (68 percent) had cortisone cream applications included in their treatment

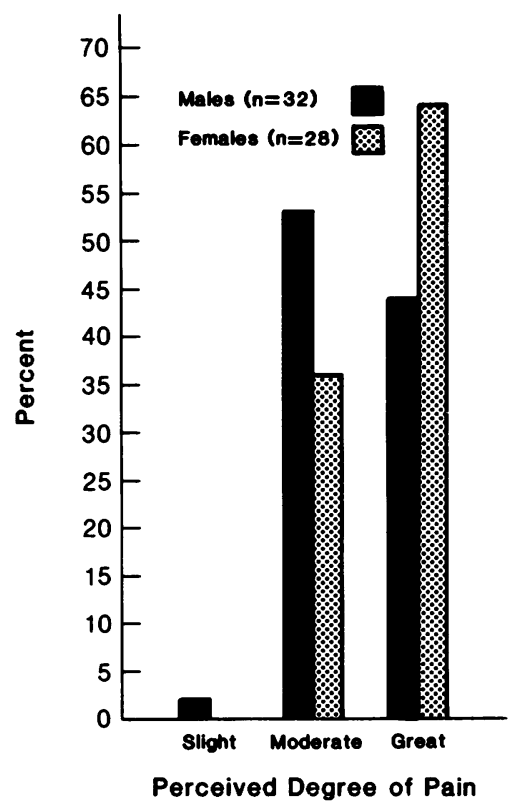

Fig. 1: Perceived degree of lateral epicondylitis pain prior to treatment, by sex.

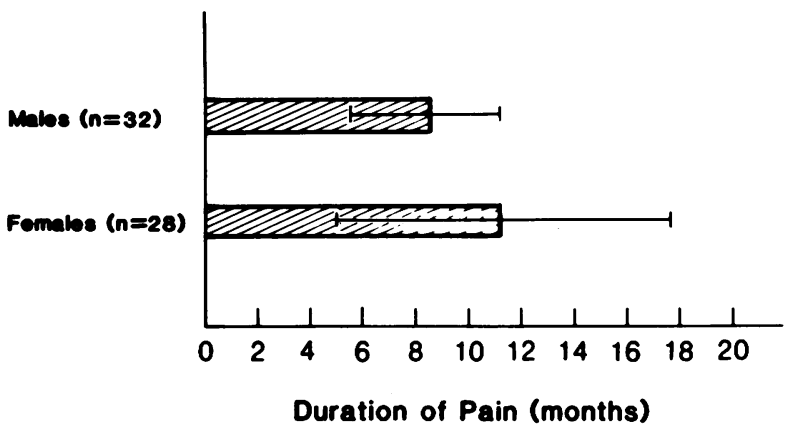

Fig. 2: Duration of lateral epicondylitis pain in months, by sex.

TABLE I

Primary activity associated with onset of lateral epicondylitis pain

\begin{tabular}{lcccc}
\hline & \multicolumn{4}{c}{ ACTIVITY* } \\
\cline { 2 - 5 } SEX & TENNIS & GOLF & RACQUETBALL & HEAVY LIFTING \\
\cline { 2 - 5 } & \multicolumn{4}{c}{ Number (Percent) } \\
\hline $\begin{array}{l}\text { Males } \\
\text { (N=32) }\end{array}$ & $11(34 \%)$ & $4(13 \%)$ & $4(13 \%)$ & $4(13 \%)$ \\
$\begin{array}{l}\text { Females } \\
\text { (N=28) }\end{array}$ & $14(50 \%)$ & $3(11 \%)$ & - & - \\
\hline $\begin{array}{l}\text { TOTAL } \\
\text { (N=60) }\end{array}$ & $25(42 \%)$ & $7(12 \%)$ & $4(7 \%)$ & $4(7 \%)$ \\
\hline
\end{tabular}

*Remaining activities identified accounted for $<5$ percent each

regimes. This percentage was greater among females (79 percent) than males (59 percent). However, the males had more cortisone treatments on the average $(X=12)$ than females $(X=8)$.

Duration of the treatment regime averaged 1.2 months for all subjects. The average length of time since the last treatment was 18.8 months $(S . E .=0.97$ ) for the total group. Neither of these findings were significantly different between males and females.

In response to the question, "What was the level of success of the treatments received for tennis elbow?" 62 percent of the total cases reported either "almost complete recovery" (22 percent) or "complete recovery" (40 p ircent). A range from no recovery to complete recovery included five levels ( $F, g .3$ ). No significant differences in the overall mean perceived success level were identified between the sexes. However, it may be noted that a much greater percentage of males ( 66 percent) than females (57 percent) identified either almost complete or complete recovery levels. Through univariate 
TABLE ॥

Number and duration of treatments for lateral epicondylitis, by $\operatorname{sex}$

\begin{tabular}{|c|c|c|c|}
\hline SEX & $\begin{array}{c}\text { TOTAL NUMBER } \\
\text { OF ALL } \\
\text { TREATMENTS }\end{array}$ & $\begin{array}{c}\text { TOTAL NUMBER OF } \\
\text { CORTISONE } \\
\text { APPLICATIONS } \\
\text { (Included in Total } \\
\text { Number of } \\
\text { Treatments) }\end{array}$ & $\begin{array}{l}\text { DURATION OF } \\
\text { TOTAL NUMBER } \\
\text { OF TREATMENTS }\end{array}$ \\
\hline & Mean \pm S.E. & Mean \pm S.E. & $\begin{array}{c}\text { (Months) } \\
\text { Mean } \pm \text { S.E. }\end{array}$ \\
\hline $\begin{array}{l}\text { Male } \\
(N=32)\end{array}$ & $13.1 \pm 2.0$ & $12.1 \pm 2.8$ & $1.4 \pm 0.271$ \\
\hline $\begin{array}{l}\text { Female } \\
(N=28)\end{array}$ & $12.5 \pm 1.4$ & $8.2 \pm 1.3$ & $1.1 \pm 0.156$ \\
\hline $\begin{array}{l}\text { TOTAL } \\
(N=60)\end{array}$ & $12.8 \pm 1.2$ & $10.0 \pm 1.5$ & $1.2 \pm 0.123$ \\
\hline
\end{tabular}

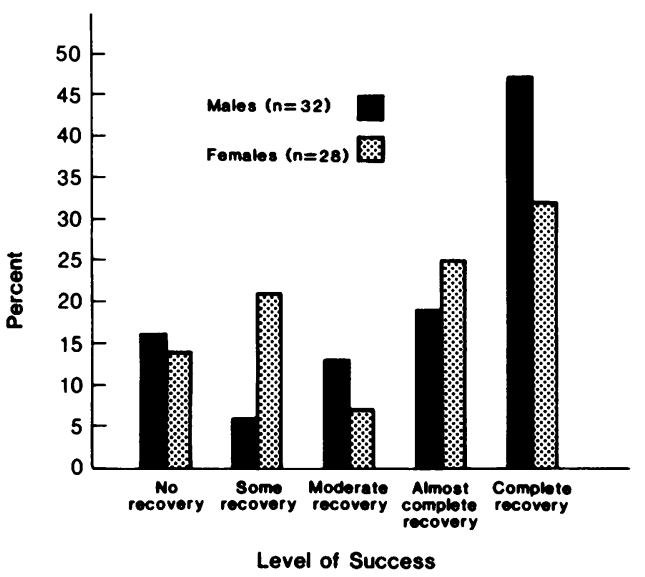

Fig. 3: Perceived level of success of treatment, by sex.

analyses, age, degree of pain, cortisone application, or duration of treatments were not associated with the level of success. However, there as a significant difference $(P<0.05)$ in the number of treatments completed by the males with a complete recovery versus those without complete recovery (17.1 and 8.8, respectively; $t=-2.21 ; p<0.05)$; this was not significantly different in the females (12.3 and 12.9, respectively), however.

An inverse relationship for the total group $(r=-0.6)$ and, by sex, was identified between the level of success and the duration of pain; for example, in the total group, the mean durations of pain, 17.3 months, 10.3 months, and 6.3 months correlated respectively with the levels of success. 0 (no recovery). 2 (moderate recovery) and 4 (complete recovery) (Fig. 4). As would be expected, signficant differences were observed between males and females $(p<0.05)$.

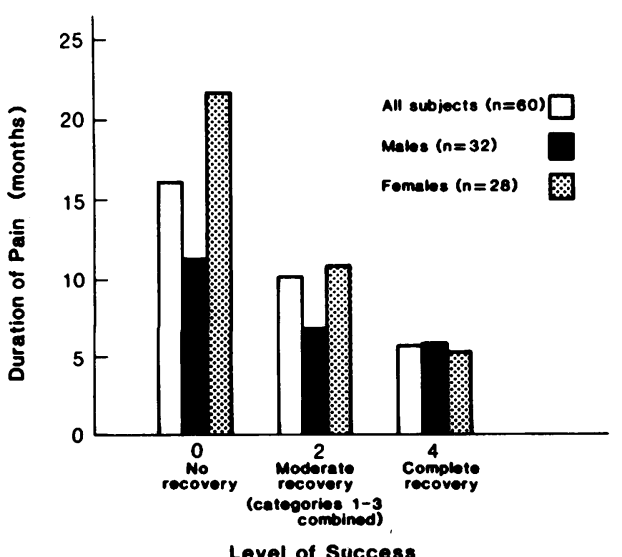

Fig. 4: Duration of lateral epicondylitis pain, by level of success, by sex.

Of the 24 individuals who reported complete recovery, seven had a recurrence of symptoms (4 male; 3 female). This recurrence was not associated with any of the variables of the treatment regime.
Subjects were asked if they ever stopped the activity(ies), during the treatment period, that they thought was associated originally with the onset of the tennis elbow pain. Responses are identified in Fig. 5 and indicate that 60 percent refrained from this activity for all of the treatment period. Subjects identifying this specific response were asked to identify when they returned to this activity(ies). Females ( $X=0.1$ month) returned to the associated activity(ies) much earlier than the males $(X=1.8$ months) accounting for significant differences ( $p<0.001)$. Interestingly, this did not have an impact on the perceived level of success or recurrence and/or change in the pain leve following treatment.

Length of Time Activity

Associated with Injury

was Eliminated

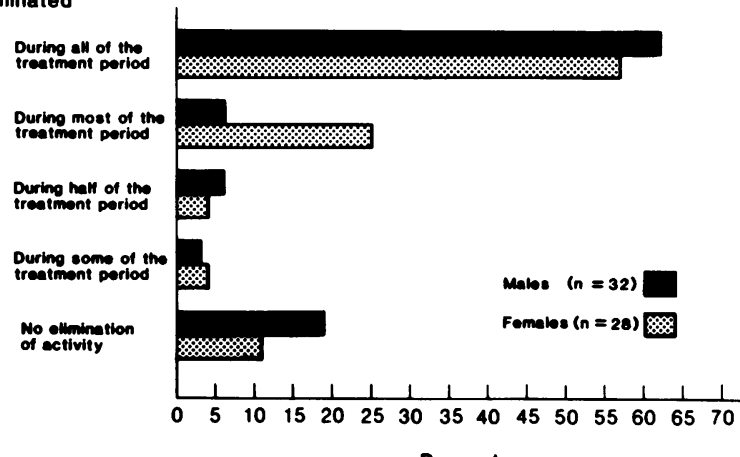

Percent

Fig. 5: Length of time activity(ies) associated with lateral epicondylitis pain was eliminated during the treatment period.

Analyses for potential association of age with each of the variables identified were conducted. Age was not associated with duration or degree of pain, return to activity, level of success, recurrence or change in pain following treatment, or the number or duration of treatments.

Multiple risk analyses were conducted to determine the most important predictors of complete recovery following treatment (Table III). To accomplish this, the variables of age, gender, duration of pain and degree of pain prior to treatment, degree of cessation of activity during treatment inclusion of cortisone treatments, total number of treatments, and duration of treatments were included in the prediction models. Because of the initial differences documented between male and female cases, separate analyses, by gender, were conducted in addition to the analysis incorporating all cases together.

TABLE III

Analyses of multiple variables in the prediction of complete recovery

MODEL SUMMARY OF MULTPLE RISK FACTOR ANALYSIS

Improvement Goodness of Fit

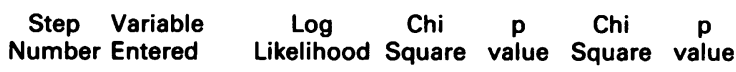

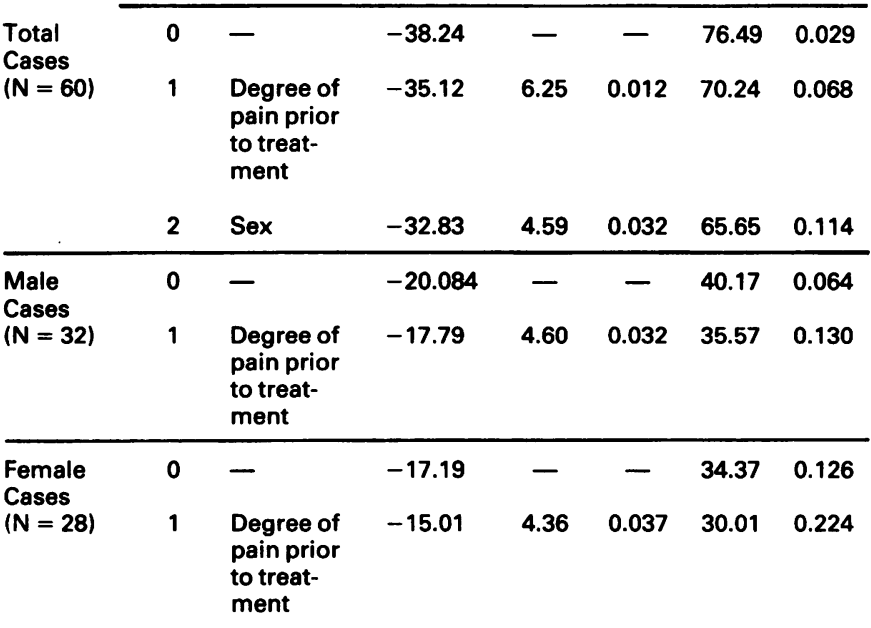

In all three models, which considered the above variables, simultaneously, the most important predictor of outcome was the degree of pain; the greater the pain, the more likely was complete recovery following treatment ( $p<$ 
0.5). In the model with all cases together, sex was the second most important predictor ( $p<0.05$ ), indicating the male sex as being associated more strongly with complete recovery. No further predictors were entered into the models given the limitations of the 0.05 significance level.

Utilisation of these models incorporating the identified variables allows one to predict the outcome of complete recovery with 75 percent accuracy, in the case of male subjects and 66 percent accuracy in the case of females. This is in contrast to the outcome identified through simple analysis revealing complete success in nine of 28 female cases (32 percent) and in 15 of 32 male cases (47 percent). In the model considering all cases together, one could expect to predict the outcome of complete recovery with 68 percent accuracy versus the $\mathbf{4 0}$ percent identified through simple analysis.

\section{DISCUSSION}

The purpose of this study was to analyse the effectiveness of a treatment for lateral epicondylitis and to identify variables related to treatment outcomes, including complete recovery. The final cases in this study included 32 males (53 percent) and 28 females (47 percent) with an average age of 43 years. This correlated closely with the findings in our previous comprehensive epidemiological study of lateral epicondylitis (Priest et al, Part 1, 1980; Priest et al, Part 2, 1980).

Complete recovery was reported by 40 percent of the total cases. This differed significantly between males (47 percent) and females (32 percent). Of the individuals with complete recovery, 29 percent reported a recurrence. Previous researchers, utilising other treatments, have identified recurrence rates ranging from 18 to 66 percent (Nevelos, 1980; Clarke et al, 1975). However, follow-up in these studies was completed six months following treatment. In our study, the recurrence rate was documented at an average of 19 months following treatment. Since the follow-up period in our study was more than three times those of the other studies, our recurrence rate compares favourably with them. Because of differences in definitions of treatment outcomes (e.g. complete recovery, etc.) from other studies, these comparisons were not possible.

Through initial analyses, duration of pain prior to treatment was identified as an important variable in the success of treatment. Those with complete success identified an average of six months pain prior to treatment versus those with moderate recovery ( 10 months) and no recovery (17 months). The implication of this result is a need for early case-finding to elicit the most favourable outcome in this treatment regime.

In addition, through the use of multiple risk factor analyses that assessed the potential impact of eight different variables upon the outcome of complete recovery versus not complete recovery, the degree of pain prior to treatment was identified as the most important predictor of recovery; the greater the pain the more likely was complete recovery following treatment. Furthermore, degree of pain was not only the best single predictor of complete recovery while controlling for multple variables; but it, also, increased the ability to predict outcome by approximately 30 percent in both males and females. The fact that males had a greater probability of complete recovery may be explained, in part, by the statistically significant differences in duration of pain prior to treatment, between males $(X=$ 8.3 months) and females ( $X=11.4$ months).

This points out a need to look not only at the simple analysis which demonstrated an association of duration of pain with level of success, but, also, to consider the simultaneous effect of multiple variables through multiple risk factor analysis which, in this case, revealed the impact of the degree of pain upon complete recovery.

While lateral epicondylitis - "tennis elbow" - is not a life-threatening problem, this condition presents the potential for long-term disability and limitation and/or cessation of regular activities, including work-related tasks. Based on this study, it would appear that costs associated with such disability, including lost-work time and rehabilitation/treatment programme costs, could be substantially reduced through early diagnosis and treatment.

\section{ACKNOWLEDGEMENTS}

The authors thank Eugene Johnson, PhD, Professor of Biometry, School of Public Health, University of Minnesota for his consultation relevant to the multple risk factor analyses and review of the manuscript and Robert P. Nirschl, MD, Orthopaedic Surgeon, Virginia Sports Medical and Rehabilitation Institute, Arlington, Virginia for his review of this manuscript.

Funding for this study was provided by: the Institute for Athletic Medicine, Fairview Hospital, Minneapolis, Minnesota; the Mendon F. Schutt Foundation, Minneapolis, Minnesota; and the Minnesota State High School League. Computer grants, providing computer time, were awarded by the University of Minnesota Computer Center and the University of Minnesota Health Sciences Computer Center.

\section{References}

Allman, F. L., 1975 "Tennis elbow: Etiology, prevention and treatment". Clin. Orthop. 3: 308-316.

Clarke, A. K. and Woodland, J., 1975 "Comparison of two steroid preparations used to treat tennis elbow, using the hypospray". Rheum. and Rehab. 14 (1): $47-49$

Cox, D. R., 1970. The Analysis of Binary Data. London: Methuen.

Dixon, W. J., Brown, M. B., Engelman, L., Frane, J. W., Hill, M. A., Jennrich, R. I. and Toporek, J. D., 1981. BMDP Statistical Software, 1981 Edition, Los Angeles: University of California Press, pp. 330-344.

Friedlander, H. L., Reid, R. L. and Cape, R. F., 1967 "Tennis elbow". Clin. Orthop. 51: 109.

Froimson, A. I., 1971 "Treatment of tennis elbow with forearm support band". J.Bone and Joint Surg. 53A: 193.

Griffin, J. E. and Touchstone, J. C., 1963 "Ultrasonic movement of cortisol into pig tissue: I. Movement into skeletal muscle". Am.J.Phys.Med. 42: 77-85.

Griffin, J. E. and Touchstone, J. C., 1965 "Ultrasonic movement of cortisol into pig tissue: II. Movement into paravertebral nerve." Am.J.Phys.Med. 44: 20-25.

Griffin, J. E., Ecternach, E. L., Price, R. M. et al, 1967 "Patients treated with ultrasonically driven hydrocortisone and with ultrasound alone". Phys.Ther. 47: 595-601.

Ilfeld, F. W. and Field, S., 1966 "Treatment of tennis elbow: Use of a special brace". JAMA 195: 111.

Kleinkort, J. A. and Wood, F., 1975 "Phonophoresis with one percent versus ten percent hydrocortisone". Phys.Ther. 55 (12): 1320-1325.

Nevelos, A. B., 1980 "The treatment of tennis elbow with triamcinolone acetonide". Curr.Med.Res.Opin. 6 (7): 507-509.

Nirschl, R. P, 1974 "The etiology and treatment of tennis elbow". J. Sportsmedicine. 2 (6): 308-323.

Nirschl, R. P., 1979 “Tennis elbow: The surgical treatment of lateral epicondylitis". JBJS 961-1 (6): 832-839.

Priest, J. D., 1976 "Tennis elbow: The syndrome and a study of average players". Minn.Med. 59: 367-371.

Priest, J. D., Braden, V. and Gerberich, S. G., 1980 "The elbow and tennis, part 1: An analysis of players with and without pain". Phys. and Sportsmed. 8 : 89-91.

Priest, J. D., Braden, V. and Gerberich, S. G., 1980 "The elbow and tennis, part 2: A study of players with pain". Phys, and Sportsmed. 8: 77-85.

US News and World Report, January 15, 1979. 